\title{
The Use of Liquid Smoke as a Substitute for Nitric Acid for Extraction of Amorphous silica from Rice husk through Sol-Gel Route
}

\author{
WASINTON SIMANJUNTAK ${ }^{1 *}$, SIMON SEMBIRING ${ }^{2}$, \\ KAMISAH, D. PANDIANGAN ${ }^{1}$, FARADILLA SYANI ${ }^{1}$ and RUDY, T. M. SITUMEANG ${ }^{1}$ \\ ${ }^{1}$ Department of Chemistry, the Faculty of Mathematics and Natural Science, \\ The University of Lampung, Indonesia. \\ 2Department of Physic, the Faculty of Mathematics and Natural Science, \\ The University of Lampung, Indonesia. \\ ${ }^{*}$ Corresponding author E-mail: Wasinton.simanjuntak@fmipa.unila.ac.id
}

http://dx.doi.org/10.13005/ojc/320435

(Received: July 19, 2016; Accepted: August 19, 2016)

\begin{abstract}
This study assessed the potential of liquid smoke as substitute for nitric acid for production of rice husk silica using sol-gel method. The efficacy of liquid smoke was compared to that of $10 \%$ $\mathrm{HNO}_{3}$ solution in terms of the volume required and the mass of silica obtained. Further evaluation was made by comparing the characteristics of the silica as revealed by several characterization techniques include Fourier infrared spectroscopy, x-ray diffraction, scanning electron microscopy, and particle size analysis. No significant difference between the volume of the liquid smoke and the $\mathrm{HNO}_{3}$ solution required, as well as between the mass of silica obtained. Both samples display practically similar functionality and structure. The most interesting finding is that the silica obtained using liquid smoke exhibits more homogeneous surface morphology and narrower particle size distribution. Considering its environmentally friendly nature, it was concluded that liquid smoke is more advantageous than $\mathrm{HNO}_{3}$ solution.
\end{abstract}

Keywords: Rice husk, silica, sol-gel, liquid smoke.

\section{INTRODUCTION}

Rice husk is an agricultural waste abundantly available in rice-producing countries, such as Indonesia. Representing around $20 \%$ mass of the whole rice ${ }^{1-3}$, rice husk is one of the most important agricultural residues in quantity. Traditionally, rice husk is considered as a non-valuable waste, and disposed primarily by burning, creating not only air pollution problems but also the extremely fine silica ash, which is also toxic. Furthermore, this treatment practice leads to production of very large amount of $\mathrm{CO}_{2}$ gas released to the atmosphere and eliminates the opportunity to utilize the silica free husk for production of valuables products as value added. However, rice husk is now considered as valuable 
resource primarily because this agriculture residue has been found to contain $15-20 \%$ by mass inorganic components, in which silica is the major constituent with the quantity of 93-99 percent $^{2}$.

In recognition of its high silica content, together with availability and renewability considerations, currently rice husk continues to gain growing interest as a potential source of silica. In addition to its high purity, rice husk silica is known as porous and amorphous material ${ }^{3,4}$, which makes it a suitable raw material for production of various silica based materials. Taking advantage of these characteristics, many researchers are currently engaged in exploration of rice husk silica potential, and a wide range of its applications has been reported in literatures, such as production of nanosilica ${ }^{4,5}$, silica gel ${ }^{6,7}$, carbosil $^{8}$, heterogeneous catalysts $^{9-12}$, aluminosilicates ${ }^{13}$, synthetic zeolites ${ }^{14-16}$, and ceramics ${ }^{17-19}$.

For production of rice husk silica, two methods have been applied extensively. The first method is thermal extraction by incinerating the husk at $500-1000^{\circ} \mathrm{C}^{20,21}$, at which all the organic components are burnt out, leaving the ash containing silica as residue. The second method is commonly known as the sol-gel method. This method involves chemical extraction of silica using alkaline solution such as $\mathrm{NaOH}^{11,22}$ or $\mathrm{KOH}^{13,18}$, taking advantage of the solubility of the silica in the alkaline solution. The filtrate (silica sol) was then acidified using strong mineral acids, such as $\mathrm{HCl}^{18}, \mathrm{HNO}_{3}{ }^{11}$ or $\mathrm{H}_{2} \mathrm{SO}_{4}{ }^{23,24}$ to bring the sol into neutral condition, at which the silica was transformed from sol into gel state.

Despite their effectiveness, strong acids are relatively expensive and harmful to environment. This is because the water used to wash the gel is finally discharged as corrosive wastewater, causing disposal problem. Considering the environmental hazard together with the price of mineral acids, and in recognition of the growing interest in rice husk silica, this study was carried out to investigate the feasibility of liquid smoke to replace mineral acid for production of silica from rice husk through sol-gel route. To the best of our knowledge, no attempt has been made to use liquid smoke for production of silica powder from rice husk.Utilization of liquid smoke was considered since liquid smoke has sufficient acidity due to the presence of phenols, carbonyls, and organic acids ${ }^{25,26}$, therefore, can be used to neutralize alkaline silica sol, as the case with mineral acids. In addition, liquid smoke is more environmentally friendly agent than strong mineral acids, and can be produced from any biomass by simple pyrolysis treatment. The potential of liquid was evaluated by comparing the amount of liquid smoke with that of $\mathrm{HNO}_{3}$ solution required, and the characteristics of the silica obtained using both agents.

\section{Experimental methods \\ Materials and instruments}

Raw rice husk was obtained from a local rice milling industry. Before use, the husk was soaked in hot water and left overnight. Floating husk was discharged, while sinking husk was collected, rinsed with distilled water, and then oven dried at $110^{\circ} \mathrm{C}$ for eight hours. Coconut shell was obtained from a local coconut charcoal industry. Sodium hydroxide and nitric acid used are reagent grade purchased from Merck. The instruments used for characterization of the sample are Varian2000 FTIR spectrometer, an automated Shimadzu XD-610 X-ray diffractometer, a Philips-XL Scanning Electron Microscope, and Particle Size Analyzer, Analysette 22 Nano Tec plus.

\section{Procedures}

Liquid smoke used in this study was prepared in our laboratory (Integrated Laboratory and Center for Technology Innovation, The University of Lampung) by pyrolysis of coconut shell at 450 ${ }^{\circ} \mathrm{C}$. Before use, liquid smoke was filtered to remove particulates and applied without further treatment. The liquid smoke was found to have the $\mathrm{pH}=1.83$.

Rice husk silica was extracted using an alkali extraction process, adopting the method previously applied ${ }^{11}$. Typical experiment was carried out by transferring 50 grams of dry husk into a beaker glass contains $500 \mathrm{~mL}$ of $5 \% \mathrm{NaOH}$ solution. The mixture was boiled for 30 minutes, and then allowed to cool to room temperature and left for 24 hours to optimize the release of silica from the husk. The mixture was filtered to separate the filtrate which contains dissolved silica (silica sol), while the residue was discharged. 
To obtain solid silica, two sol samples with equal volume of $200 \mathrm{~mL}$ were placed in separate beaker glass. The first sample was neutralized by drop wise addition of $10 \% \mathrm{HNO}_{3}$ solution until the sol was completely converted into gel, and the second sample was treated similarly using liquid smoke. The gels were aged overnight, and then rinsed repeatedly with distilled water to remove the excess of acid or liquid smoke. The gel was oven dried at $110^{\circ} \mathrm{C}$ for eight hours, and the mass of solid silica was weighed. Solid silica was ground into powder and sieved with 200 mesh sieve, for characterization.

\section{Characterization}

To compare the characteristics of silica obtained using $\mathrm{HNO}_{3}$ with that obtained using

Table 1: Comparison of sol-gel process to obtained rice husk silica using $\mathrm{HNO}_{3}$ and liquid smoke

\begin{tabular}{lccc}
\hline Agent & Run & $\begin{array}{c}\text { Volume } \\
\text { required }(\mathbf{m L})\end{array}$ & $\begin{array}{c}\text { Mass of } \\
\text { silica }(\mathbf{g r})\end{array}$ \\
\hline $\mathrm{HNO}_{3}$ solution & 1 & 25.5 & 3.92 \\
$(10 \%)$ & 2 & 25.8 & 3.88 \\
& 3 & 26.1 & 3.91 \\
Liquid smoke & 1 & 27.4 & 3.87 \\
& 2 & 26.8 & 3.93 \\
& 3 & 27.7 & 3.96 \\
\hline
\end{tabular}

liquid smoke, both samples were characterized using different techniques. The functionality of the sample was evaluated using FTIR spectroscopy carried out on a Perkin Elmer FTIR spectrometer. For measurement, the silica was mixed with solid $\mathrm{KBr}$ of spectroscopy grade and converted into pellet by pressing. To produce FTIR spectrum, the sample was scanned over the wave number range of $4000-400 \mathrm{~cm}^{-1}$.Structural evaluation using XRD technique was conducted using CuKa radiation $(\lambda=1.5418 \AA)$, produced at $40 \mathrm{kV}$ and $30 \mathrm{~mA}$, with a $0.15^{\circ}$ receiving slit, recording the pattern over goniometry $(2 q)$ range of $10-40^{\circ}$ with a step size of 0.02 , using post-diffraction graphite monochromator with a Nal detector. Microstructural analysis was conducted on polished and thermally-etched sample. Particle size distribution was studied using wet method with distilled water as dispersing solvent..

\section{RESULTS AND DISCUSSION}

\section{Sol-gel process}

To assess the potential of liquid smoke, the sol-gel process was evaluated in terms of the volume of liquid smoke required as compared to that of $\mathrm{HNO}_{3}$ solution and the mass of solid silica obtained using each agent. For this purpose, sol-gel process using each of the agents was carried out in triplicate, and the results obtained are presented in Table 1.

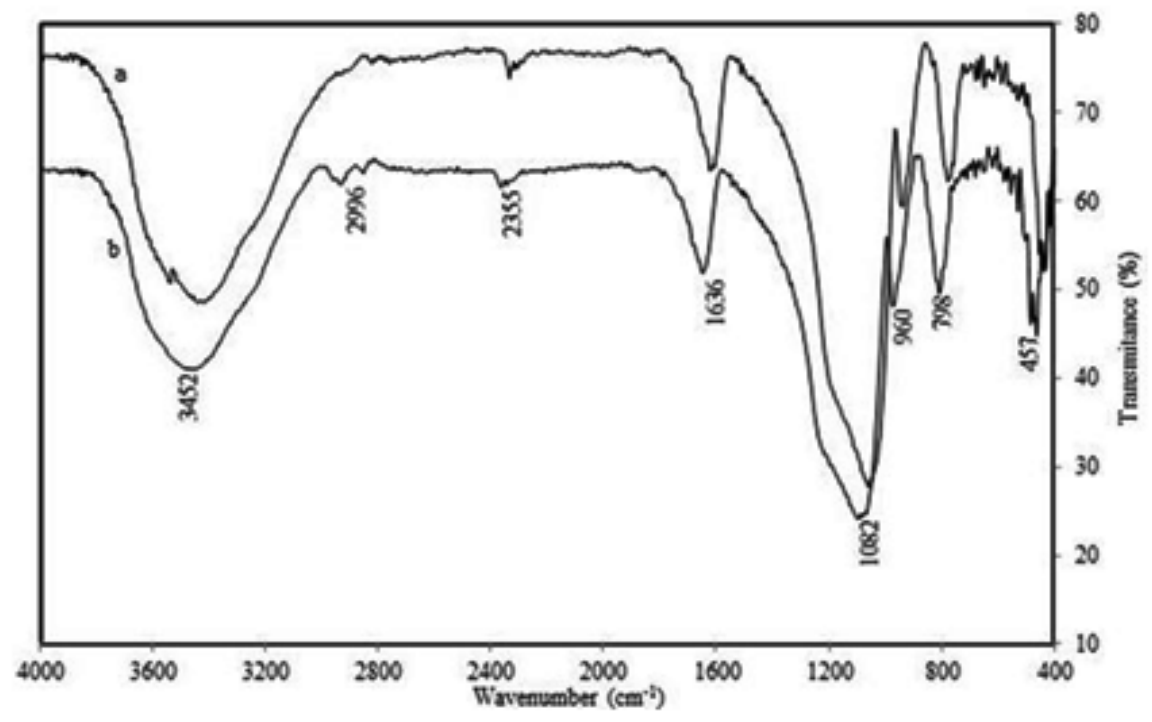

Fig. 1: The FTIR spectrum of rice husk silica produced using $\mathrm{HNO}_{3}$ solution (a), and using liquid smoke (b) 
The experimental data presented in Table 1 clearly indicate that no significant difference between the volume of liquid smoke and $\mathrm{HNO}_{3}$ solution required and the mass of silica obtained. These findings clearly demonstrated that liquid smoke is comparable to $10 \% \mathrm{HNO}_{3}$ solution, reflecting the potential of liquid smoke to replace mineral acids for sol-gel production of rice husk silica.Further evaluations were based on several characteristics of the silica as described below.

\section{Characteristics of silica}

To compare the functionality of the silica obtained using $\mathrm{HNO}_{3}$ solution and that of silica obtained using liquid smoke, both samples were characterized using FTIR spectroscopy produced the spectra as presented in Figure 1. As can be seen, the spectra are practically very similar, characterized by the existence of several absorption bands associated with rice husk silica commonly reported in literatures $22,24,27-29$. The broad band centered at around $3452 \mathrm{~cm}^{-1}$ region is attributed to stretching vibration of hydroxyl $(-\mathrm{OH})$ group of silanol $(\mathrm{Si}-\mathrm{OH})$ in the silica and adsorbed water molecules on the surface of the silica. The existence of $\mathrm{Si}-\mathrm{OH}$ bond is supported by a weak and shoulder band centered at around $980 \mathrm{~cm}^{-1}$, and the presence of adsorbed water molecules is supported by the absorption band centered at around $1636 \mathrm{~cm}^{-1}$, which is attributed to bending vibration of the $\mathrm{O}-\mathrm{H}$ bond. The $\mathrm{Si}-\mathrm{O}-\mathrm{Si}$ bond in the structural framework of the siloxane in the silica is indicated by three characteristic bands, associated with different vibration modes of the bond, i.e.the band centered at $1082 \mathrm{~cm}^{-1}$, the band centered at $798 \mathrm{~cm}^{-1}$, and the band centered $457 \mathrm{~cm}^{-1}$, which are attributed to asymmetric stretching vibration, symmetric stretching vibration, and bending vibration of the Si-O-Si bond, respectively
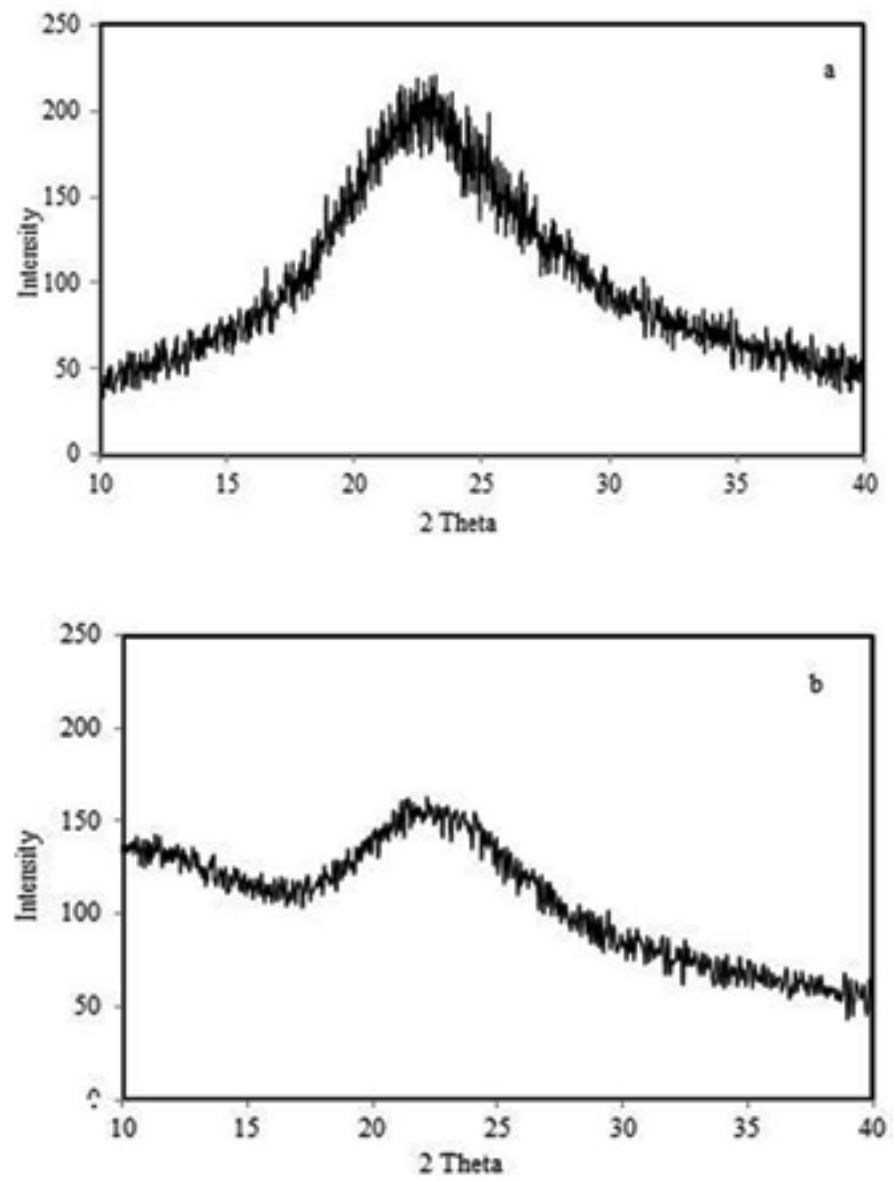

Fig. 2: XRD pattern of rice husk silica obtained using nitric acid (a) and using liquid smoke (b) 

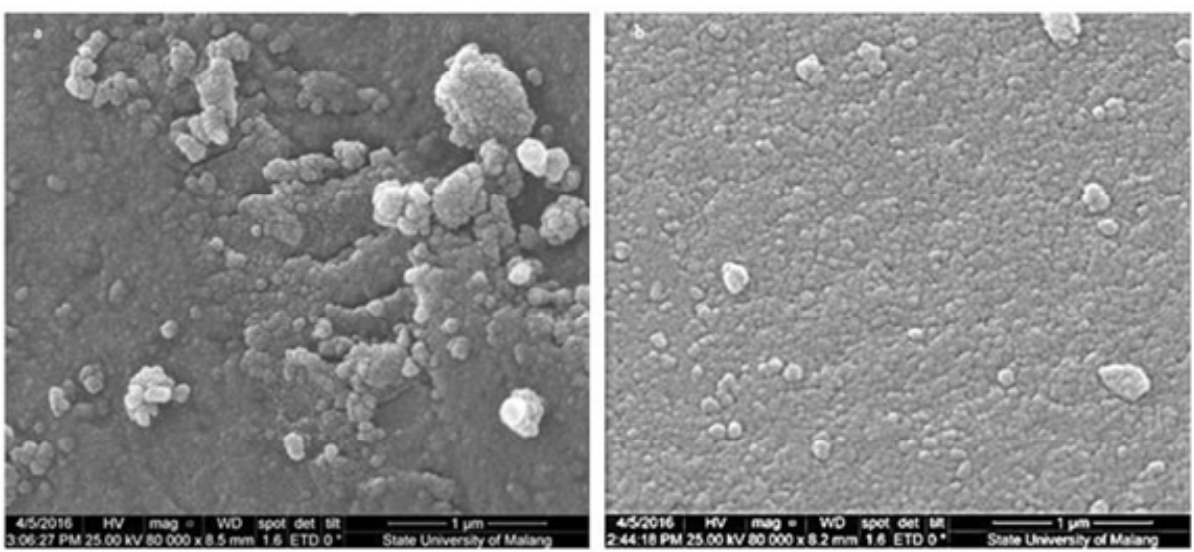

Fig. 3: SEM micrographs of rice husk silica obtained using $\mathrm{HNO}_{3}$ solution (a), and using liquid smoke (b)
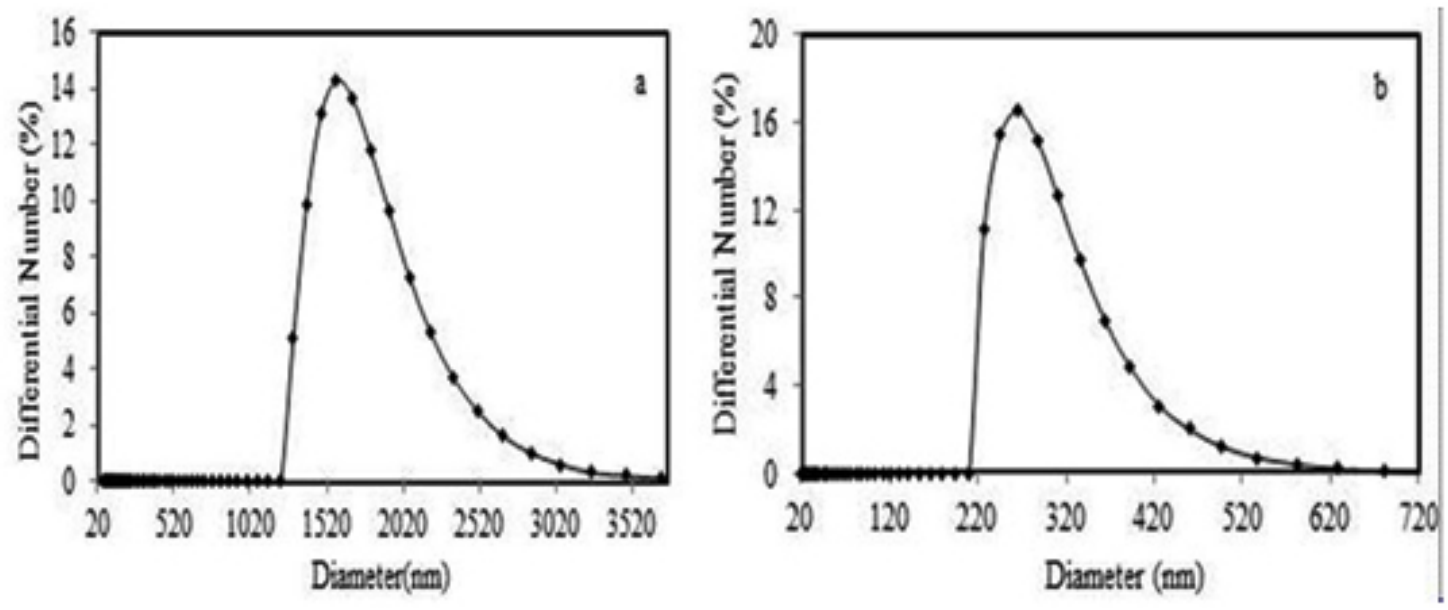

Fig. 4: Particle size distribution of the sample obtained using nitric acid solution (A) and using liquid smoke (B)

In the spectra, small peaks were observed at $2996 \mathrm{~cm}^{-1}$ represent symmetric and asymmetric $-\mathrm{CH}_{2}$ stretching vibrations respectively and at 2355 $\mathrm{cm}^{-1}$ represents-CO vibration. The emerge of these organic related functional groups is most likely due to the presence of organic impurities originating from the husk or from the liquid smoke used in the process.

Characterization of the samples using XRD technique was carried out to evaluate the crystallographic structure of the sample which signifies whether the sample is amorphous or crystalline phase. The XRD patterns of the samples are shown in Figure 2. As generally reported in the literatures 22,30 , the diffraction patterns clearly indicate the existence of the samples as amorphous materials. This amorphous sate of the silica is characterized by the presence of a broad peak centered at $2 q=21.6^{\circ}$ (PDF-27-1615).Comparing the patterns it can be observed that the peak for the silica obtained using liquid smoke is broader than that of the silica obtained using $\mathrm{HNO}_{3}$ solution, suggesting that the sample produced using liquid smoke is more amorphous.

To compare the effect of $\mathrm{HNO}_{3}$ solution and liquid smoke on microstructures of the samples, both samples were characterized using the technique of SEM, and the surface images produced are shown in 
Figure 3. As can be seen, the two samples displayed significantly different surface morphologies, in which the surface homogeneity of the sample obtained using liquid smoke is significantly higher than that of the sample obtained using nitric acid solution. As can be seen, the surface of the sample obtained using $\mathrm{HNO}_{3}$ solution is marked by the existence of larger particle sizes and very evident presence of clusters with different sizes, spread all over the surface. The sample obtained using liquid smoke, on the other hand, is characterized by the presence of only a few clusters with considerably smaller sizes than those observed in the sample obtained using nitric acid solution. These different surface characteristics demonstrated that liquid smoke is able to suppress the agglomeration of the silica molecules during the gelation step, thus leading to smaller particle sizes, which is very advantageous in the context of solid material production using sol-gel technique.

For further evaluation of the particle size profile, both samples were characterized using PSA technique, and the results obtained are shown in Figure 4.

As can be seen, the particle size distributions of the samples are significantly different, in which very evident smaller particle sizes and narrower range of the particle distribution is displayed by the sample obtained using liquid smoke. The sample obtained using nitric acid solution has the size in the range of $1142-3712 \mathrm{~nm}$, while that obtained using liquid smoke has the particle size in the range of $194-680 \mathrm{~nm}$. It should be noted that the particle size distributions of two samples are not perfectly symmetric, which most likely due to the presence of aggregates as evidently revealed by the SEM results in Figure 3.

\section{CONCLUSION}

The results of this study demonstrated the efficacy of liquid smoke as substitute for mineral acids for production of rice husk silica using sol-gel technique. The volume of liquid smoke required and the mass of silica obtained are comparable to those of $10 \% \mathrm{HNO}_{3}$ solution. The most interesting results are more homogeneous surface morphology and narrower particle size distribution of the silica obtained using liquid smoke than those of the silica produced using $\mathrm{HNO}_{3}$ solution. These different surface characteristics demonstrated that liquid smoke is able to suppress the agglomeration of the silica molecules during the gelation step, which is very advantageous in the context of solid material production using sol-gel technique. Considering the performance and environmentally friendly nature of liquid smoke, it is then concluded that utilization of liquid smoke for production of rice husk silica is more advantageous than $\mathrm{HNO}_{3}$ solution, and more likely than other mineral acids.

\section{ACKNOWLEDGMENT}

The authors gratefully acknowledge The Directorate of Higher Education, The Ministry of Research, Technology, and Higher Education, Republic of Indonesia, for financial support through research grant, Hibah Kompotensi 2016, contract number: 78/UN26/8/LPPM/2016.

\section{REFERENCES}

1. Olamide , O. and Oyawale, F. A. Int. J. Sci. Tech.2012, 2, 210-213.

2. Ugheoke, B. I., Mamat, O., andWahjoedi, B.A.J. Aust. Ceram. Soc.2013, 49, $92-100$

3. Shelke, V.R., Bhagade, S.S., and Mandavgane, S. A. Bull.Chem. React. Eng. Catal.2010, 5, 63-67.

4. Amutha, K., Ravibaskar, R. and Sivakumar, G. Int. J. Nano Tech. Appl. 2010, 4, 61-66.

5. Yuvakkumara, R., Elangoa, V., Rajendrana, V., and Kannanb, N. J. Exp. Nanosci.2014, 9, $272-281$.
6. Qi, T. and Tao, W. J. Supercrit. Fluids,2005, 35, 91-94.

7. Rungrodnimitchai, S., Phokhanusai, W., and Sungkhaho, N. J. Met. Mater. Miner.2009, 19, 45-50.

8. Simanjuntak, W., Sembiring, S., and Sebayang, K. Indo. J. Chem.2012, 12, 119-125

9. Adam, F., Kandasamy, K., and Balakrishnan, S. J. Colloid. Interface Sci.2006, 304, 137143.

10. Ahmed, A. E. and Adam, F. Micropor. Mesopor. Mat.2007, 103, 284-295. 
11. Pandiangan, K. D. and Simanjuntak, W. Indo. J. Chem. 2013, 13, 47-52.

12. Pandiangan, K. D., Jamarun, N., Arief, S., and Simanjuntak, W. Orient. J. Chem.2016, 32, 385-390.

13. Simanjuntak, W., Sembiring, S., Manurung, P., Situmeang, R., and Low, I. M. Ceram. Int. 2013, 39, 9369-9375

14. Kardatos, K., Gavela, S., Ntziouni, A., Pistiolas, K. N., Krytsi, A., and Rigopoulou, V. K-.Micropor. Mesopor. Mat.2008, 115, 189196.

15. Rahman, M. M., Hasnida, N., and Wan Nik, W. B.J. Sci. Res. 2009, 1, 285-291.

16. Ali, I. O., Hassan, A. M., Shaaban, S. M., and Soliman, K. S.Sep. Purif. Technol. 2011, 83, 38-44.

17. Sembiring, S. (2011). Indo. J. Chem. 2011, 11, $85-89$.

18. Sembiring, S., Simanjuntak, W., Manurung, P., Asmi, D., and Low, I. M. Ceram. Int.2014, 40, 7067-7072.

19. Sembiring, S., Simanjuntak, W., Situmeang, R., Riyanto, A., and Kerista, S. Ceram. Int.2016, 14, 8431-8437

20. Rozainee, M., Ngo, S. P., Arshad, A. S. and Tan, K. G. Energy Sustain.Dev.2008, 12, 33-42.
21. Rafiee, E., Shahebrahimi, S., Feyzi, M. and Shaterzadeh, M. Int. Nano Let.2012, 12, 1-8.

22. Yuvakkumara, R., Elangoa, V., Rajendrana, V., and Kannanb, N. J. Exp. Nanosci.2014, 9, $272-281$.

23. Awizar, D. A., Othman, N. K., Jalar, A., Daud, A. R., Rahman, I. A., and Al-hardan, I. N. Int. J. Electrochem. Sci. 2013, 8,1759 - 1769.

24. UI Haq, I., Akhtar, K., and Abdul Malik, A. J. Chem. Soc. Pak. 2014, 36, 382-387.

25. Simon, R., de la Calle, B., Palme, S., Meier, D., and Anklam, E. J. Sep. Sci. 2005, 28, 871-882.

26. Wititsiri, S. J. Sci. Technol. 2011, 33, 349354.

27. Guo Y., Wang M., Zhang H., Liu G., Zhang L. and Qu X.J. Appl. Polym. Sci.2008, 107, 2671-2680.

28. Dominic , M. C. D., Begum, S. P. M., Joseph, R., Joseph, D., Kumar, P. and Ayswarya E. P. Int. J.Sci. Environ.Technol.2013, 2, 1027-1035.

29. Abadi, M. H. S., Delbari, A., Fakoor, Z., and Baedi, J. J. Ceram. Sci. Tech. 2015, 06, 4146

30. Edson, L. F. and Ederson, G. J. Mat. Sci. Tech.2006, 9, 206-215. 